\title{
Space-planning development of high-rise dominating structures in the historical center (case study of St. Petersburg)
}

\author{
Milena Zolotareva ${ }^{1^{*}}$ \\ ${ }^{1}$ Saint Petersburg State University of Architecture and Civil Engineering, Vtoraya Krasnoarmeyskaya \\ St. 4, St. Petersburg, 190005, Russia,
}

\begin{abstract}
The article addresses the evolution of layout and spatial design development regarding high-rise zoning in the central part of St. Petersburg. The skyline has always played an important role in the spatial composition of St. Petersburg. Study objective of the study is to analyze the evolution of the spatial and spatial structure and high-altitude zoning in the historical part of St. Petersburg in the end of the 19th - beginning of the 20th century. A study of the sustainable development of the historical urban environment is of undoubted interest from the point of view of identifying promising approaches to the implementation of planning, architectural and construction measures for for modern construction in the historical city. The study is based on cartographic, literary end field methods. St. Petersburg is a unity of space-planning structures that were shaped during the 18th-19th centuries. Moreover, every subsequent urbanplanning concept of city development acted both to develop the city and to connect the concepts to each other. Therefore, regularities in the development of the system of high-rise dominating structures in St. Petersburg shall be analyzed with account for the historical stages of the layout shaping of its urban environment. Analysis of examples of new construction at the beginning of the 19th - beginning of the 20th century in the center of St. Petersburg allows you to capture a change in the urban landscape. The practice of active transformation of the city center was accompanied by changes with regard to the height range and scale, and, sometimes, replacement of the existing spatial structure and high-rise zoning.
\end{abstract}

\section{Introduction}

In a city like St. Petersburg, matters of preserving the historical landscape take on particular significance. The historical landscape of St. Petersburg is determined by the period of city origin, main formation stages of its planning, functional and spatial structure, common characteristics of environmental elements [1].

When it comes to the formation of historical territories in St. Petersburg, it should be noted that they are characterized by continuous development in time. This development is

${ }^{*}$ Corresponding author: goldmile@yandex.ru 
associated with the continuity of layout and material forms, which, in its turn, is expressed in the architectural and spatial multi-layering. Virtually all historical periods of city development left a mark on its layout or have been reflected in its buildings.

\section{Development of high-rise characteristics of the historical center in St. Petersburg: specifics}

\subsection{Main development stages of visual dominating structures in St. Petersburg}

St. Petersburg was founded in 1703, and the basics of its city-planning framework were shaped during the $18^{\text {th }}$ century [2]. The first high-rise structures characterizing the city skyline had mainly strategic and religious significance. The city skyline was dominated by the bulwarks of the Peter and Paul Fortress, Admiralty, Peter and Paul Cathedral, and Old Trinity Cathedral (Fig. 1).

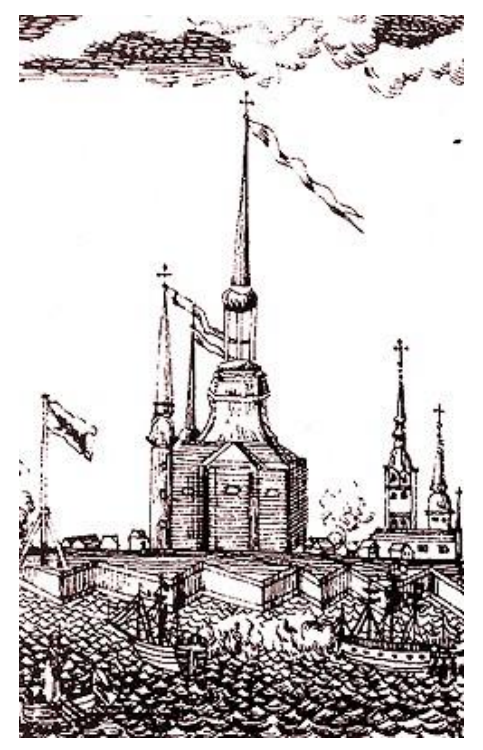

Fig. 1. Wooden church of Saints Peter and Paul within the fortress. V. Ruban. $18^{\text {th }}$ century.

By the mid-19 $9^{\text {th }}$ century, a single architectural and planning structure developed. It reinforced the system of squares, avenues and streets with the assemblage of ensembles and dominating structures [3]. On the banks of the Neva River, a single compositional ensemble developed [4] in the form of interrelating main dominating structures on the left and right banks of the Neva River, as well as high-rise buildings that shaped the skyline of other city districts (Admiralty part, Vasilyevsky Island, Kolomna, Petrovsky Island, Smolny Convent district). Regulating the height range of ribbon development made it possible to identify the main visual landmarks in the layout system of St. Petersburg (Fig. 2). At the end of the $19^{\text {th }}$ - beginning of the $20^{\text {th }}$ century, the layout of the city actively developed. It was filled with variety [5]. While some structures of the $18^{\text {th }}$ - beginning of the $19^{\text {th }}$ century were kept in the city, at the end of the $19^{\text {th }}$ century, the loose fabric of the city was filled with buildings constructed in the eclectic, modernist and retrospective styles, which significantly changed the altitude characteristics of the city landscape. It is the structures that were built at the turn of the century that mainly define the nature of the mass housing development today. 


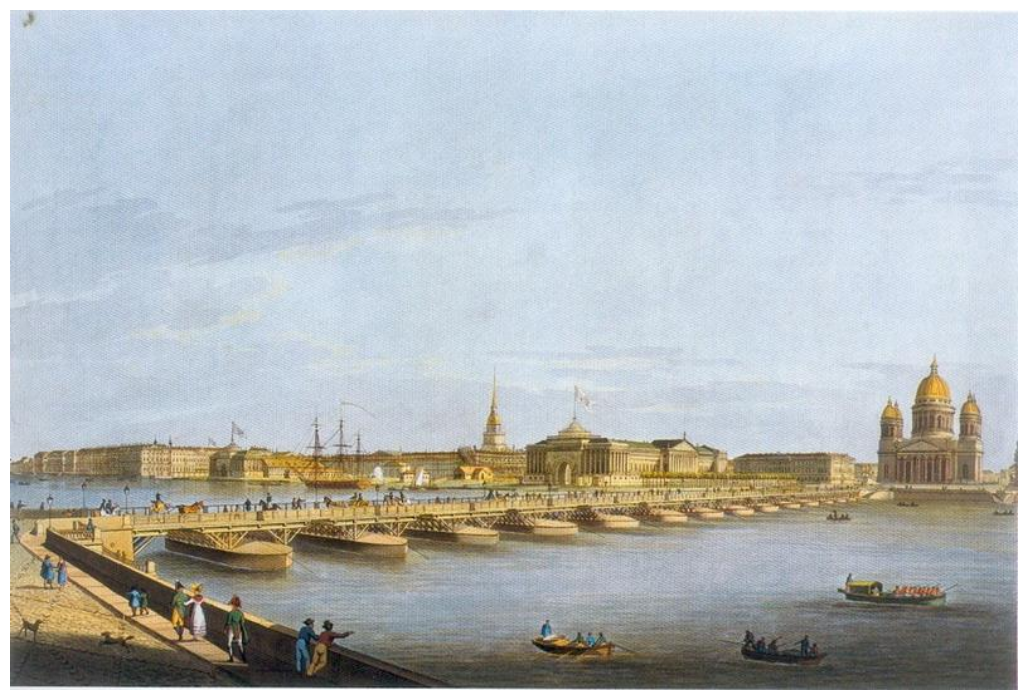

Fig. 2. View over the Saint Isaac's Bridge, Winter Palace and Admiralty, a drawing of 1840.

Simultaneously, at the end of the $19^{\text {th }}$ - beginning of the $20^{\text {th }}$ century, the city-planning traditions of the St. Petersburg development were reviewed and its spatial structures were adjusted. While until the mid- $19^{\text {th }}$ century, city development was characterized by minimum loss of environmental elements, the years that followed saw qualitative changes in the spatial complex of the capital and its landscape components. These processes were a consequence of contradictions between the existing city environment and the needs of society.

\subsection{Main factors of changes in the nature of visual landmarks in city areas}

The city of the end of the $19^{\text {th }}$ - beginning of the $20^{\text {th }}$ century changed its development path. The establishment of St. Petersburg as a large industrial and trading center entailed an increase in its size and population, changes in the value of land in its center, changes in stylistic preferences, activation of functions that required attractiveness of the environment (trade, banks, cultural and entertainment facilities, luxury residential buildings). These factors changed the nature of many avenues and streets in St. Petersburg. At the end of the $19^{\text {th }}$ - beginning of the $20^{\text {th }}$ century, the means of architectural expression used in the system of dominating structures changed as well [6]. A shift away from the classicism with its universalism and transition to the freedom of form-making created new compositional strategies. Simultaneously, the overall height range of buildings, both in the center and in the periphery, changed [7]. Structures that had been visual landmarks in the past were overbuilt with "high-rise" buildings. Land plots in possession became larger. Five- and sixstory buildings were constructed in those areas. That, in its turn, led to the overall enlargement of the urban environment.

A new type of visual landmarks occurred. Those were local dominating structures whose visibility was limited by a small area of immediately adjacent territories. Such dominating microstructures mainly laid emphasis on the intersections of streets. They included towers, projecting bay windows, rounded corners of buildings topped with various domed forms [8]. 


\subsection{Nature of visual accents in the historical center at the beginning of the 20th century}

In the $19^{\text {th }}$ century, a three-story merchant house of the Lapins was located at 11 Zagorodny Prospekt /40 Rubinshteina Street. Fig. 3 shows the overall dependence of the environment on a dominating structure located at the Vladimirskaya Square at the beginning of Zagorodny Prospekt - the bell turret of the Our Lady of Vladimir Church. In 1913-1914, three areas were united where architect A.L. Lishnevsky built a house distinguished by its neoclassical plasticity and being an active dominant structure on the corner (Fig. 4). The new visual accent changed the general context of the environment; a new visual center on Zagorodny Prospekt in the area of Five Corners appeared. Razyezzhaya Street and Rubinshteina Street also looked to the towered building.

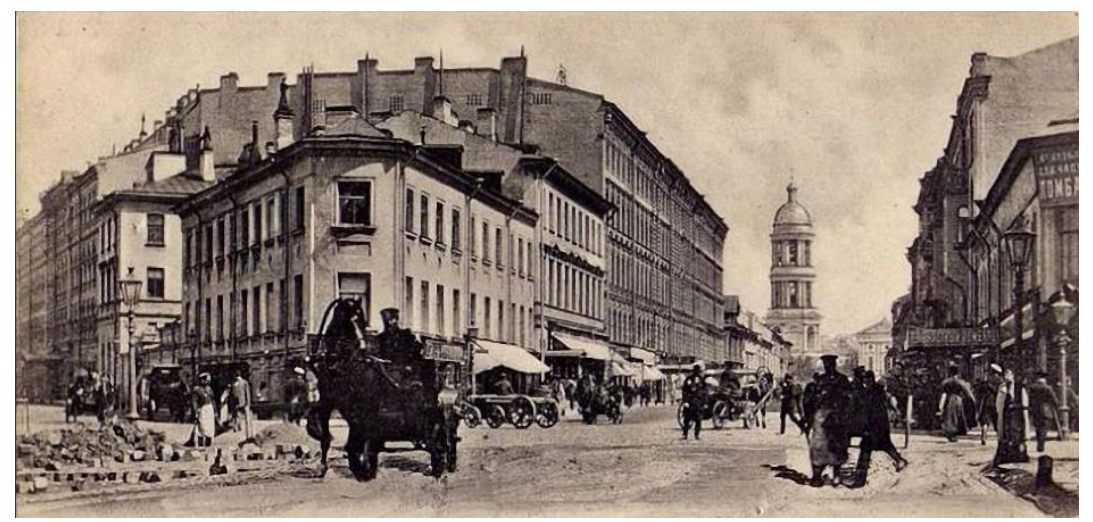

Fig. 3. 11 Zagorodny Prospekt / 40 Rubinshteina Street. End of the $19^{\text {th }}$ century

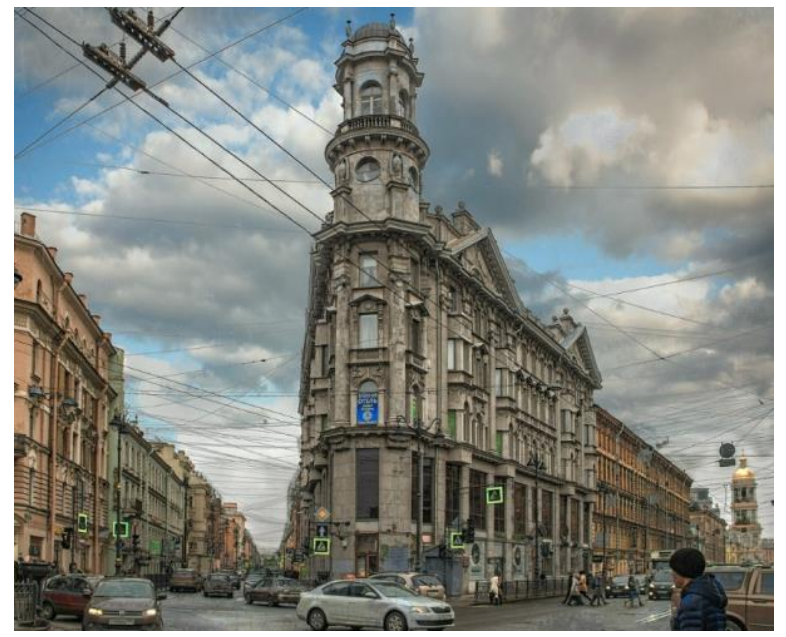

Fig. 4. Rental house of Sh.-Z. Korf. 11 Zagorodny Prospekt/40 Rubinshteina Street, 1913-1914, architect: A.L. Lishnevsky.

Construction of the Esders and Scheefhals merchant house on the corner of the Moyka River embankment and Gorokhovaya Street can serve as an example of similar destruction of the structured environment of the $18^{\text {th }}-19^{\text {th }}$ centuries. Being a central street included in the trident structure, Gorokhovaya Street looks to one of the main dominating structures of St. Petersburg - the Admiralty. Fig. 5 shows that before the beginning of the $20^{\text {th }}$ century, 
on the corner of the Moyka River embankment, there was a three-story building with a high half-basement. In 1905, the City Council permitted the construction of a new building for the Esders and Scheefhals business on this land plot.

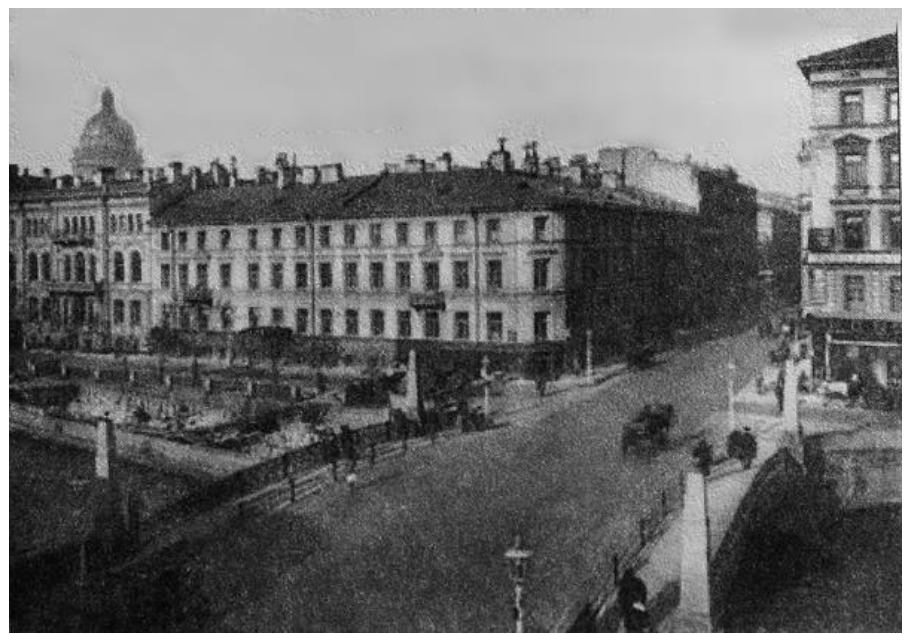

Fig. 5. View of the Moyka River embankment near the Red Bridge

The building for the Au Pont Rouge store was constructed in 1906-1907 by architects V.A. Lipsky and K.N. de Rochefort in the eclectic modernist style (Fig. 6). The use of a metal frame made it possible to change the traditional fine-meshed facades to large forms of a row of show windows with narrow partition walls. A high attic was built above the fifth floor. The new structure not only contradicted the overall environmental scale of the Moyka River embankment. As a result of constructing the tower on the corner of the plot, the overall context of the place and traditional orientation of the environment to the Admiralty building were disrupted.

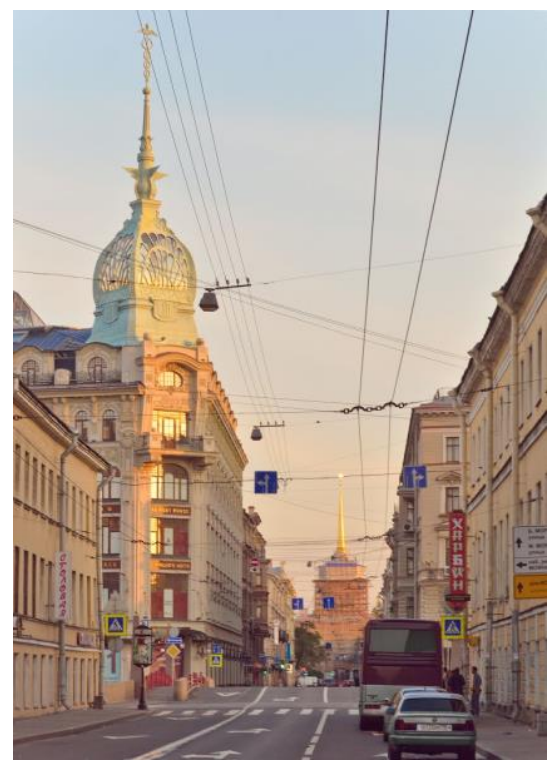

Fig. 6. Esders and Scheefhals merchant house. 1906-1907, architects: V.A. Lipsky, K.N. de Rochefort. 


\subsection{New visual accents in the historical environment of the central street of St. Petersburg - Nevsky Prospekt}

Let us consider the influence of new requirements for the formation of functional and planning structures on the architectural and spatial environment of Nevsky Prospekt. It is sufficient to compare its landmarks of the beginning of the $19^{\text {th }}$ century depicted by V.S. Sadovnikov (Panorama of Nevsky Prospekt) with its changed image at the turn of the century [9].

The landscape of Nevsky Prospekt of the $18^{\text {th }}$ - beginning of the $19^{\text {th }}$ century represents a unity of the architectural and space-planning environment (Fig. 7) supplemented by the rhythmic pattern of dominating structures that were mainly religious (St. Peter's Church, St. Catherine's Church, St. Catherine's Armenian Apostolic Church, Kazan Cathedral) and pulsating lacunae connecting Nevsky Prospekt with the central ensembles of the city (ensembles of the Palace Square, Kazan Cathedral Square, Ostrovsky Square, Arts Square), but the turn of the $19^{\text {th }}$ and the $20^{\text {th }}$ centuries changed this view. The functional and spatial structure of Nevsky Prospekt was reformed, and the "central" functions of its individual parts and the whole territory were strengthened [10].

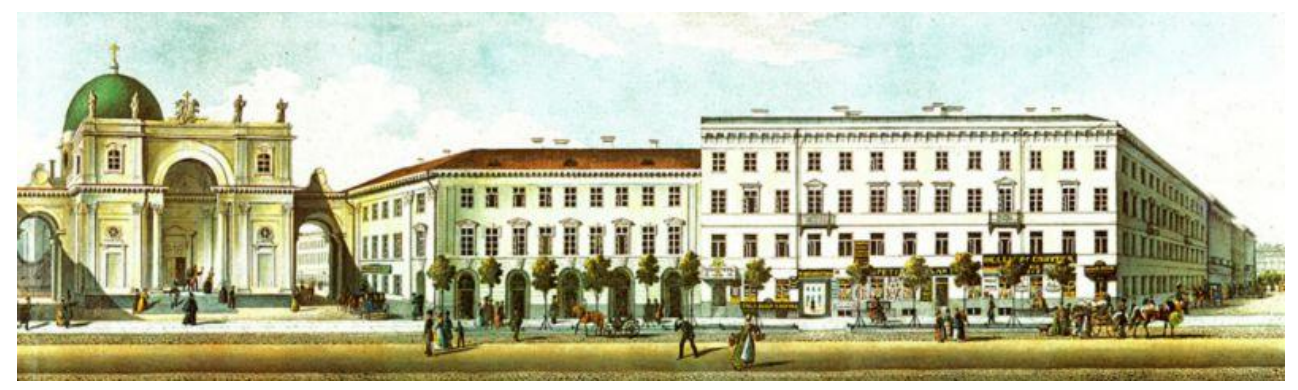

Fig. 7. Fragment of the Panorama of Nevsky Prospekt with the St. Catherine's Cathedral. V.S. Sadovnikov

Also, changes in the general nature of the architectural landscape of Nevsky Prospekt included a new arrangement of its landmarks. Either large-scale buildings (Wawelberg merchant house - 7-9 Nevsky Prospekt (Fig. 8), Mertens trade house - 21 Nevsky Prospekt (Fig. 9), Brothers Eliseevs trade house - 56 Nevsky Prospekt, Passage - 48 Nevsky Avenue, etc.) or buildings aspiring to become new dominating structures (Singer house - 28 Nevsky Prospekt) (Fig. 10) acted as environmental landmarks.

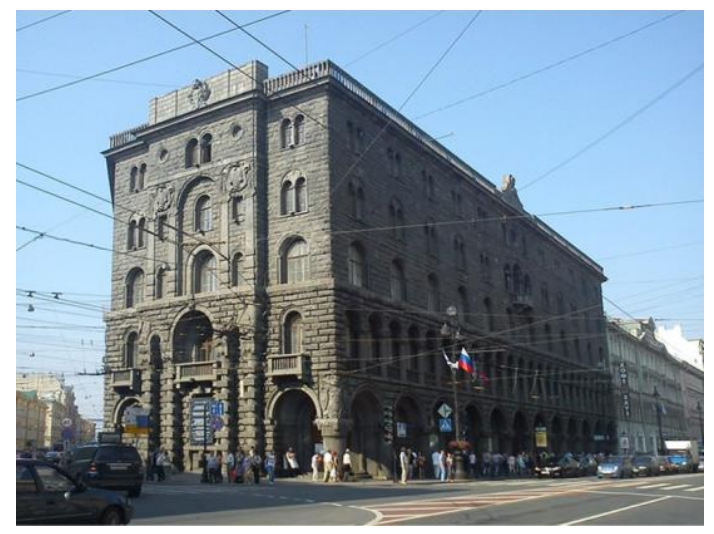

Fig. 8. Wawelberg merchant house, 7-9 Nevsky Prospekt 


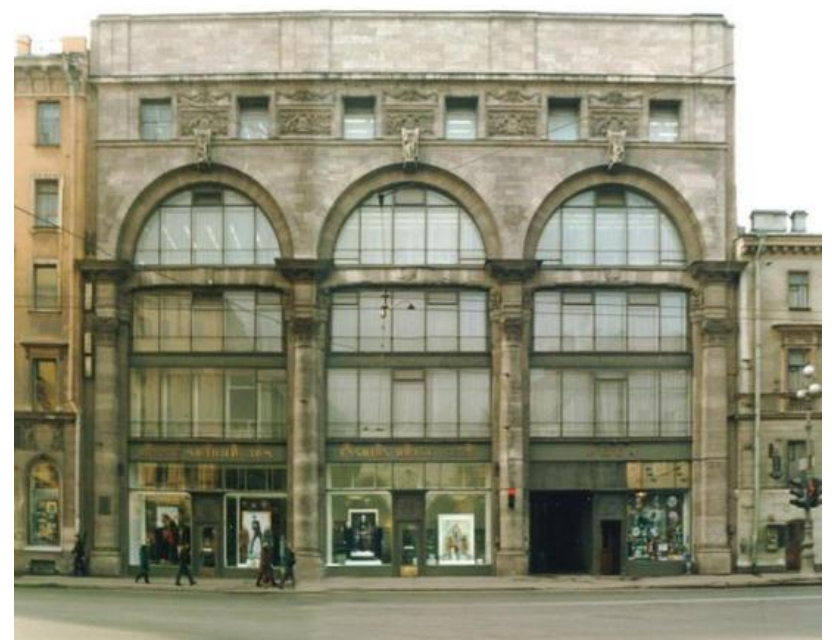

Fig. 9. Mertens trade house, 21 Nevsky Prospekt

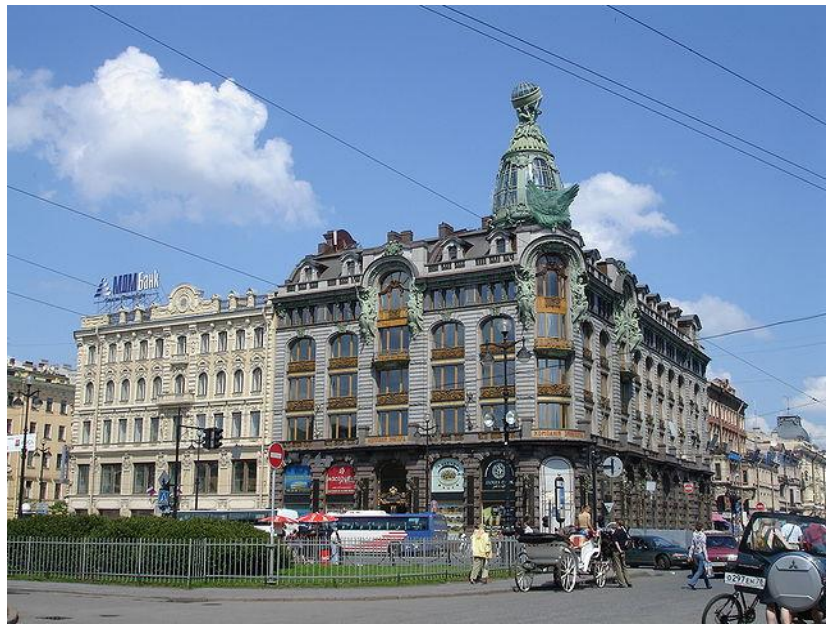

Fig. 10. Singer house, 28 Nevsky Prospekt

The composition of the facades of most buildings was based on the contrast comparison of the large scale of lower stories with the smaller scale of upper stories, which is characteristic of the eclecticism period. The changes in the stylistics had an impact on the spatial structure of Nevsky Prospekt: local dominating structures (bay windows and other elements of the architectural plastics of the facade) characteristic of the eclectic and modernist styles appeared here [11]. These elements determine the axial composition of buildings or "fix" corners of structures at the intersection of Nevsky Prospect and perpendicular main roads.

\section{Conclusions}

Based on the analysis of principles of the spatial and layout development of the high-rise zoning in the central part of St. Petersburg, it is possible to make the following conclusions:

1. The first high-rise structures that defined the skyline of the city at the beginning of its construction had mainly strategic significance. 
2. The central compositional ensemble of the capital was formed on the banks of the Neva River by the 1730 s.

3. The perfect spatial composition of St. Petersburg created by the first half of the $19^{\text {th }}$ century makes it one of the best pieces of the global city-planning art. Large ensembles of the Palace Square, Senate Square, Arts Square and Alexandrinsky Theater Square, the Spit of Vasilyevsky Island, etc. were built during this period.

5. Urban-planning transformations carried out in St. Petersburg in the second half of the $19^{\text {th }}$ - at the beginning of the $20^{\text {th }}$ century were typical for a city that was a large developing industrial center. That was accompanied by an increase in the population and, therefore, urban densification in the center and development in the suburbs. The city grew both into the depth of the area and along the banks of the Neva River.

6. At the end of the $19^{\text {th }}$ - beginning of the $20^{\text {th }}$ century, the means of architectural expression used in the system of dominating structures changed. Local dominating structures occurred whose visibility was limited by a small area of immediately adjacent territories. Such dominating microstructures mainly laid emphasis on the intersections of streets. They included towers, projecting bay windows, rounded corners of buildings topped with various domed forms.

Thus, the practice of active transformation of the city center in the $18^{\text {th }}$ - beginning of the $20^{\text {th }}$ century was accompanied by changes in the landscape with regard to the height range and scale, and, sometimes, replacement of the existing spatial structure and high-rise zoning.

\section{References}

1. D. Shvidkovsky Russian Architecture and the West (New Haven: Yale University Press, 2007)

2. Complete Collection of Laws of the Russian Empire: the First Collection 1834 (Saint Petersburg: Printing Office of the Second Department of His Imperial Majesty's Own Chancellery) 5, (1834)

3. M. Zolotareva, Journal of Architecture and Urbanism, 41 (1), 71-77 (2017)

4. J. Kurbatov and V Gorjunov, World Applied Sciences Journal, 4, 203-206 (2013)

5. D. Shvidkovsky The Founding of Petersburg and the History of Russian Architecture (State Academy of the Fine Arts of Russia), 66, 79-97 (2005)

6. M. Zolotareva Regulating Architectural and Civil Engineering Process in Russia in the $18^{\text {th }}$ Century (Saint Petersburg: Saint Petersburg State University of Architecture and Civil Engineering, 2008)

7. Complete Collection of Laws of the Russian Empire: the First Collection (Saint Petersburg: Printing Office of the Second Department of His Imperial Majesty's Own Chancellery), 17, (1882)

8. M. Zolotareva Regulating Architectural and Civil Engineering Process in Russia in the $19^{\text {th }}$ - the Beginning of the $20^{\text {th }}$ Century (Saint Petersburg: Saint Petersburg State University of Architecture and Civil Engineering, 2008)

9. Complete Collection of Laws of the Russian Empire: the First Collection (Saint Petersburg, Printing Office of the Second Department of His Imperial Majesty's Own Chancellery) 48 (1895)

10. Yu. I. Kurbatov Petrograd. Leningrad. Saint Petersburg: Architectural and urban planning lessons SPb. (Art Of St. Petersburg, 2008)

11. S. P. Zavarikhin Modern construction in the historical center of St. Petersburg Proc. of the Scientific and Practical Conference "Modern Problems of History and Theory of Architecture” (Saint Petersburg: Saint Petersburg State University of Architecture and Civil Engineering, 2015) 